\title{
DESIGN, SYNTHESIS, AND DOCKING OF SULFADIAZINE SCHIFF BASE SCAFFOLD FOR THEIR POTENTIAL CLAIM AS INHA ENOYL-(ACYL-CARRIER-PROTEIN) REDUCTASE INHIBITORS
}

\author{
PRABHA THANGAVELU*, SIVAKUMAR THANGAVEL
}

Department of Pharmaceutical Chemistry, Nandha College of Pharmacy, Erode - 638 052, Tamil Nadu, India. Email: drtpappa@yahoo.com

Received: 8 May 2018, Revised and Accepted: 14 June 2018

ABSTRACT

Objective: An effort was made to design and synthesize the series of sulfadiazine building blocks as a targeted candidate for antimycobacterial activity.

Method: The synthesized compounds were subjected to preliminary in silico screening study for testing their antimycobacterial action by doing their molecular docking study on bioinformatics software, molecular operating environment 2009.10.

Result: The results obtained from this tool showed that there is a best docking affinity score of these target compounds against the enzyme InhA Enoyl-(acyl-carrier-protein) reductase from Mycobacterium tuberculosis (MTB) pathogen, which is one of the key enzymes involved in the type II fatty acid biosynthesis pathway of MTB.

Conclusion: Thus, the synthesized sulfadiazine Schiff base derivatives might serve as the best drug candidate for the existence of menacing pathogen MTB.

Keywords: Antimycobacterial activity, Sulfadiazine Schiff base, Molecular docking study.

(C) 2018 The Authors. Published by Innovare Academic Sciences Pvt Ltd. This is an open access article under the CC BY license (http://creativecommons. org/licenses/by/4. 0/) DOI: http://dx.doi.org/10.22159/ajpcr.2018.v11i10.27179

\section{INTRODUCTION}

Tuberculosis (TB), which is an airborne infectious disease caused predominantly by Mycobacterium tuberculosis (MTB), is a global health problem and a leading cause of death among adults in the developing country. At present among the 8 million TB infected individual, around 2 million people will die due to this active TB. To defeat this situation, now a day there are several treatment techniques has been followed to fight this TB. Besides the antibiotic treatment is one of the best methods to fight this TB condition [1-3]. Owing to the complicated shape and cell wall constituents of the mycobacterium, this will make the many antibiotics into ineffective and hinders the entry of drugs. Multidrug resistance TB [4] is a serious threat to TB control and prevention. The emergence of multidrug resistance has forced to the development of new class of therapeutic agents. Therefore, there is an interest in search of alternative antibiotics used as anti- TB agents. Among such agents, sulfonamides are structural analogs of para-aminobenzoic acid (PABA), inhibiting competitively the dihydropteroate synthase and blocking the folic acid synthesis pathway and cell division [5-7]. The most of the compounds having sulfonamide moiety in its structure may have the antibacterial [8,9], carbonic anhydrase inhibitor [10], antiviral [11], antifungal [12], anti-inflammatory activities [13,14], antitumor [15], and antithyroid activity $[16,17]$. Schiff base of sulfonamides entity has also been shown to exhibit an antifungal, antibacterial, antimalarial, antiproliferative, anti-inflammatory, antiviral, and antipyretic properties [18]. Sulfadiazine is one of the sulfanilamide derivatives that are used as an antibacterial as well as an antimalarial drug and thought to act as PABA competitive inhibitor [19]. Moreover, it possesses $\mathrm{SO}_{2} \mathrm{NH}$ moiety as an important group for their antimycobacterial activity. Based on these facts, new Schiff base derivatives tagged with sulfadiazine moiety were proposed and presented in this article.

Due to the global impact of this overwhelming disease, several different strategies such as targeting bacterial virulence, high-throughput screening, structure-based drug discovery, chemical modifications of the known drugs, and combinatorial chemistry have been explored to search for novel biologically important molecules [20]. Computer-based (in silico) molecular modeling (bioinformatics and cheminformatics) is quite useful for this purpose because they are extremely fast and costefficient and can be applied even when a compound is not physically available.

Keeping this point discussed in above paragraph, and based on previously reported research work [21], we have decided to combine the two pharmacophores for testing their antimycobacterial activity, namely, sulfadiazine with an aromatic aldehyde into one molecule, i.e., Schiff base entity. Many kinds of literature revealed that the Schiff bases are the key intermediates for the synthesis of numerous bioactive medicinal compounds from the primary amine [22]. In recent years, the chemistry of Schiff bases contains N-donor atom which has been extensively studied and has acquired a great interest because of the azomethine RHC=N-R1 linkage, where R and R1 are alkyl, aryl, cycloalkyl, or heterocyclic groups which is essential for its biological activity $[23,24]$. Before stepping into its pharmacological evaluation on MTB, we have decided to go for their in silico docking study using Molecular Operating Environment (MOE) 2009.10 software for its affinity toward the receptor protein enoyl-acyl carrier protein (ACP) reductase, which is isolated from MTB pathogen.

\section{METHODS}

All the chemicals in this synthesis were of AR and LR grade and were obtained from Merck, Hi-Media, and Sigma-Aldrich, SD Fine chem., Mumbai. All the chemicals were used as received without further purification.

\section{Experimental section}

Melting points were determined in open capillaries on a Thomas Hoover apparatus and are uncorrected. The synthesized compounds were characterized by the following methods: IR spectra of synthesized compounds were recorded on Shimadzu (8300, Kyoto, Japan) and Fourier-transform infrared spectrophotometer in the range of $4000 \mathrm{~cm}^{-1}-400 \mathrm{~cm}^{-1}$ using $\mathrm{KBr}$ pellet technique. Proton nuclear magnetic resonance (NMR) spectra were recorded using BRUKER $300 \mathrm{MHz}$ NMR Spectrometer using the solvent deuterated chloroform. Chemical shifts (d) were recorded in parts per million (ppm) and trimethylsilane used as an internal standard. 
General procedure for the synthesis of sulfadiazine Schiff base analogs (S1-S9)

An equimolar quantity of sulfadiazine $(0.1 \mathrm{M})$ and aromatic aldehyde $(0.1 \mathrm{M})$ was dissolved in $15 \mathrm{ml}$ of ethanol and then added a catalytic amount of glacial acetic acid into it and refluxed for 6-8 h, and the reaction time may depend on the aldehyde which we used for this synthesis. Completion of the reaction was confirmed by thin-layer chromatography. The reaction mixture was then poured into ice-cold water, and the obtained precipitate was filtered and dried. The product was recrystallized from absolute ethanol. The reaction sequences for synthesized compounds leading to the formation of new compounds are outlined in Fig. 1.

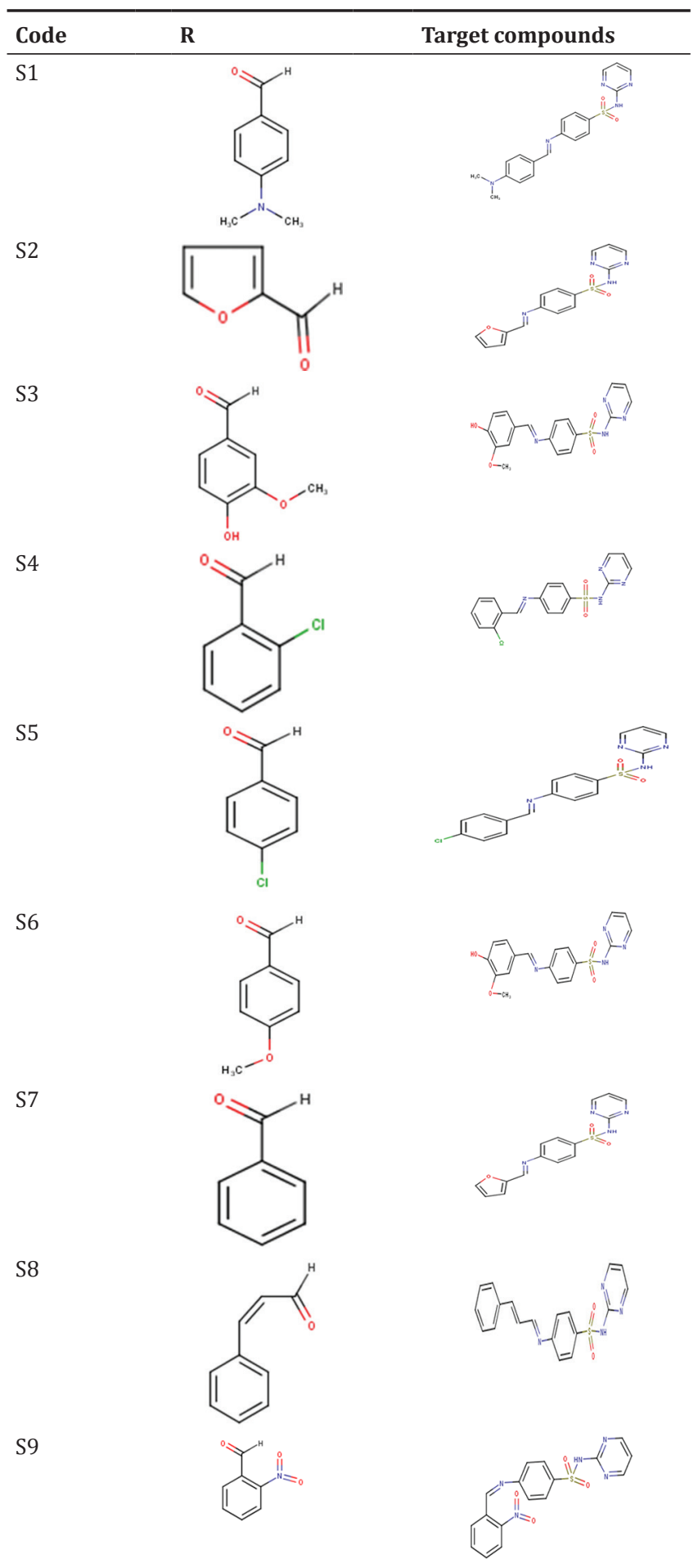

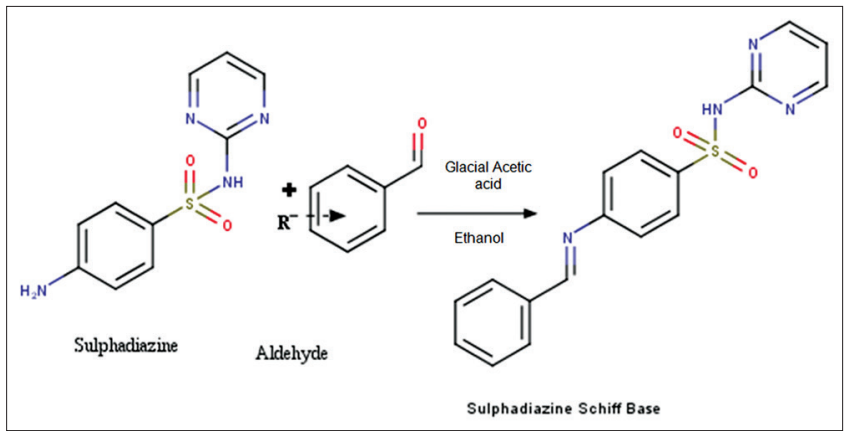

Fig. 1: Schematic representation for the synthesis of sulfadiazine Schiff base

\section{Molecular docking study}

In modern drug designing scenario, the molecular docking is commonly used for the understanding of target-receptor binding interaction and is quite often used to predict the binding orientation of target molecule of the lead with their protein receptor to find the affinity of that target compound [25]. Keeping this in mind, we undertook to design novel antimycobacterial candidates, which will target promisingly with the enzymes involved in the biosynthesis of microbial cell wall. To rationalize the biological results of our compounds, an in silico molecular docking studies with the enoyl-ACP reductase (InhA) of MTB were carried out to determine the best conformation. Enoyl-ACP reductase (ENR) is a key enzyme of the type II fatty acid synthesis system [26].

\section{Software used}

The designed structures of nine sulfadiazine Schiff base derivatives were generated using Marvin_Windows-x64_18.8 version. Marvin Sketch is an advanced chemical tool for illustrating the chemical structures, queries, reactions, etc. [27]. Then, the structures were viewed on Marvin Viewer screen to generate the SMILES notation and to IUPAC name of the synthesized compounds. The target ligand files for the molecular docking studies were built on MOE 2009.10 by Chemical Computing Group (https:// www.chemcomp.com/MOE-Molecular_Operating_Environment.htm).

\section{Preparation of target ligand files}

The molecular geometries were drawn and correct 3D structures were ensured and were followed by energy optimization at a standard MMFF94 force field level, with a $0.0001 \mathrm{kcal} / \mathrm{mol}$ energy gradient convergence criterion [28]. The molecule builder of MOE program was used for this purpose, and after building the molecule, it was energy minimized, potential energy and partial energy were corrected, and then, it was saved as molecular database (mdb) file in a local directory for the further process.

\section{Preparation of receptor}

The crystal 3D structure of enzyme enoyl-ACP reductase (Protein Data Bank file: 2NSD) was obtained from Protein Data Bank (http://www. rcsb.org/pdb). The pdb file was imported to MOE suite where receptor preparation module was used to prepare the protein. All the bound water molecules and hetero atom were removed from the complex using sequence (SEQ) window which is default in MOE program. Both polar and non-polar hydrogens were added and 3D structure was corrected. The 3-D protonated structure was energy minimized. Since the protein was devoid of associated ligand, the pocket was identified using the active site finder module of the MOE. To visualize the binding pocket, alpha spheres were created followed by the generation of dummy atoms on the centers of these spheres. The pockets were found to be deep small canyons lined with the key residues including both hydrophobic and hydrophilic amino acids.

\section{Docking methodology}

The optimized target ligands were docked with the enzymes enoyl-ACP reductase (PDB: 2NSD) protein using the MOE, 2009.10. For docking 
simulations, the placement was set as triangular matcher, rescoring was set as London $\mathrm{dG}$, the number of retaining was set as 10 , and the refinement was set as force field on MOE suite to generate 10 poses of each target ligand confirmations. As a result of docking run, the mdb. output files were created with scoring and multiple conformations of each compound. All the docked conformations were analyzed, and the best-scored pose for each compound was selected for further interaction studies. Besides, the ligand-receptor interaction followed by surface analysis of the selected best pose ligand molecule was generated on MOE suite and viewed for interpretation.

\section{RESULT AND DISCUSSION}

The new series of sulfadiazine aldehyde Schiff base derivatives were synthesized and evaluated for their in silico antimycobacterial activity. The synthesized compounds were obtained in reasonable yield. The percentage yield and melting point of the synthesized compounds were recorded and presented uncorrected. IR and $1 \mathrm{H}$ NMR spectral data of synthesized compounds were given below.

$\mathrm{S}_{1}: \quad 4-[(\mathrm{E})-\{4-($ dimethyl amino)phenyl]methylidene $\} a m i n o]-\mathrm{N}-$ (pyrimidin-2-yl)benzene-1-sulfonamide. Yellowish-orange solid; yield - 90\%; m.p - 240-260 ${ }^{\circ} \mathrm{C}$. IR $\gamma\left(\mathrm{cm}^{-1}\right)(\mathrm{KBr}): 3266 \mathrm{~cm}^{-1}(\mathrm{~N}-\mathrm{H} \mathrm{str})$; $3075 \mathrm{~cm}^{-1}$ (C-H Ar str); $1569 \mathrm{~cm}^{-1}$ (HC=N); $1520 \mathrm{~cm}^{-1}$ (C=C Ar). ${ }^{1} \mathrm{H}$ NMR $\delta$ ppm (TMS): 8.43(1H, S, CH=N), 8.60-6.81 (m, 12H, Ar-H), $3.08(\mathrm{~m}$, methyl)

$\mathrm{S}_{2}: \quad-4-\{(\mathrm{E})-[($ oxolan-2-yl) methylidene $]$ amino $\}-\mathrm{N}-($ Pyrimidin-2yl) benzene-1-sulfonamide. Brown solid; yield-82\%; m.p - 270-276 ${ }^{\circ} \mathrm{C}$. IR $\gamma\left(\mathrm{cm}^{-1}\right)(\mathrm{KBr}): 2978 \mathrm{~cm}^{-1}$ (C-H Ar str); $3280 \mathrm{~cm}^{-1}$ (N-H str); $1633 \mathrm{~cm}^{-1}$ $(\mathrm{HC}=\mathrm{N}) ; 1578 \mathrm{~cm}^{-1}$ (C=C Ar). ${ }^{1} \mathrm{H}$ NMR $\delta$ ppm (TMS): 8.46(1H, S, CH=N), 8.45-6.93 (m, 11H, Ar-H)

$\mathrm{S}_{3}: \quad 4-\{(\mathrm{E})-[(4-H y d r o x y-3-m e t h o x y \quad$ Phenyl)methylidene]amino $\}-\mathrm{N}-$ (pyrimidin-2-yl)benzene-1-sulfonamide. Yellow solid; m.p - $224^{\circ} \mathrm{C}$; yield - 81\%. IR $\gamma\left(\mathrm{cm}^{-1}\right)(\mathrm{KBr}): 3070 \mathrm{~cm}^{-1}$ (C-H Ar str); $3589 \mathrm{~cm}^{-1}(\mathrm{O}-\mathrm{H})$; $3224 \mathrm{~cm}^{-1}$ (N-H str); $1620 \mathrm{~cm}^{-1}(\mathrm{HC}=\mathrm{N}) ; 2807 \mathrm{~cm}^{-1}$ (C-H Ar str). ${ }^{1} \mathrm{H}$ NMR $\delta$ ppm (TMS): $8.89(1 \mathrm{H}, \mathrm{S}, \mathrm{CH}=\mathrm{N}), 8.51-7.47(\mathrm{~m}, 11 \mathrm{H}, \mathrm{Ar}-\mathrm{H})$.

$\mathrm{S}_{4}: \quad 4-\{(\mathrm{E})-[(2-$ chlorophenyl)methylidene $]$ amino $\}-\mathrm{N}-($ Pyrimidin-2yl) benzene-1-sulfonamide. Slight yellowish solid; m.p - 200-210 ${ }^{\circ} \mathrm{C}$; yield - 77\%. IR $\gamma\left(\mathrm{cm}^{-1}\right)(\mathrm{KBr}): 3020 \mathrm{~cm}^{-1}\left(\mathrm{C}-\mathrm{H}\right.$ Ar str); $3289 \mathrm{~cm}^{-1}(\mathrm{~N}-\mathrm{H}$ str); $1620 \mathrm{~cm}^{-1}(\mathrm{HC}=\mathrm{N}) ; 1582 \mathrm{~cm}^{-1}\left(\mathrm{C}=\mathrm{C}\right.$ Ar str). ${ }^{1} \mathrm{H}$ NMR $\delta \mathrm{ppm}$ (TMS): $8.67(1 \mathrm{H}, \mathrm{S}, \mathrm{CH}=\mathrm{N}), 8.41-7.40(\mathrm{~m}, 12 \mathrm{H}, \mathrm{Ar}-\mathrm{H})$.

$\mathrm{S}_{5}: \quad 4-\{(\mathrm{E})-[(4-$ chlorophenyl)methylidine $]$ amino $\}-\mathrm{N}-($ Pyrimidin-2yl) benzene-1-sulfonamide.light yellowish solid; yield - 75\%; m.p - 220$240^{\circ} \mathrm{C}$. IR $\gamma\left(\mathrm{cm}^{-1}\right)(\mathrm{KBr}): 3020 \mathrm{~cm}^{-1}$ (C-H Ar str); $3289 \mathrm{~cm}^{-1}$ (N-H str); $1620 \mathrm{~cm}^{-1}(\mathrm{HC}=\mathrm{N}) ; 1582 \mathrm{~cm}^{-1}\left(\mathrm{C}=\mathrm{C}\right.$ Ar str). ${ }^{1} \mathrm{H}$ NMR $\delta \mathrm{ppm}$ (TMS): $8.66(1 \mathrm{H}, \mathrm{S}, \mathrm{CH}=\mathrm{N}), 8.45-7.52(\mathrm{~m}, 12 \mathrm{H}, \mathrm{Ar}-\mathrm{H})$.

$\mathrm{S}_{6}$ : 4-\{(E)-[(C4-methoxy phenyl)methylidene $]$ amino $\}-\mathrm{N}-($ Pyrimidin2-yl-) benzene-1-sulfonamide. light yellowish solid; yield - 70\%; m.p - 220-240 ${ }^{\circ} \mathrm{C}$. IR $\gamma\left(\mathrm{cm}^{-1}\right)(\mathrm{KBr}): 2972 \mathrm{~cm}^{-1}$ (C-H Ar str); $3272 \mathrm{~cm}^{-1}$
(N-H str); $1610 \mathrm{~cm}^{-1}(\mathrm{HC}=\mathrm{N}) ; 1572 \mathrm{~cm}^{-1}$ (C=C Ar str). ${ }^{1} \mathrm{H}$ NMR $\delta \mathrm{ppm}$ (TMS): $8.60(1 \mathrm{H}, \mathrm{S}, \mathrm{CH}=\mathrm{N}), 7.90-7.08(\mathrm{~m}, 12 \mathrm{H}, \mathrm{Ar}-\mathrm{H}), 3.82\left(\mathrm{~s}, 3 \mathrm{H}, \mathrm{OCH}_{3}\right)$.

$\mathrm{S}_{7:} \quad 4$-[(E)-benzylidene amino]-N-(Pyrimidin-2-yl) benzene-1Sulfonamide. Yellowish white solid; yield - 80\%; m.p - 200-210 ${ }^{\circ} \mathrm{C}$. IR $\gamma\left(\mathrm{cm}^{-1}\right)(\mathrm{KBr}): 3002 \mathrm{~cm}^{-1}$ (C-H Ar str); $3290 \mathrm{~cm}^{-1}$ (N-H str); $1615 \mathrm{~cm}^{-1}$ $(\mathrm{HC}=\mathrm{N}) ; 1584 \mathrm{~cm}^{-1}$ (C=C Ar str). ${ }^{1} \mathrm{H}$ NMR $\delta \mathrm{ppm}$ (TMS): $8.65(1 \mathrm{H}, \mathrm{S}$, $\mathrm{CH}=\mathrm{N})$, 8.00-7.42 (m, 12H, Ar-H) 7.52-7.82 (Ar benzene).

$\mathrm{S}_{8}: 4-[(\mathrm{E})-[(2 \mathrm{E})-3$-phenylprop-2-en-1-ylidene] amino]-N- (pyrimidin-2yl) benzene-1-sulfonamide. Yellowish solid; yield - 70\%; m.p - 215$210^{\circ} \mathrm{C}$. IR $\gamma\left(\mathrm{cm}^{-1}\right)(\mathrm{KBr}): 3072 \mathrm{~cm}^{-1}$ (C-H Ar str); $3285 \mathrm{~cm}^{-1}$ (N-H str); $1631 \mathrm{~cm}^{-1}(\mathrm{HC}=\mathrm{N}) ; 1735 \mathrm{~cm}^{-1}$ (C=C Ar str). ${ }^{1} \mathrm{H}$ NMR $\delta \mathrm{ppm}$ (TMS): $7.48(1 \mathrm{H}, \mathrm{S}, \mathrm{CH}=\mathrm{N}), 8.45-6.79(\mathrm{~m}, 13 \mathrm{H}, \mathrm{Ar}-\mathrm{H}) ., 6.80-7.22(\mathrm{~s}, 2 \mathrm{H}, \mathrm{C}=\mathrm{C})$

$\mathrm{S}_{9}: \quad 4-\{(E)-[(2-n i t r o p h e n y l) m e t h y l i d e n e]$ amino $\}-N$-(pyrimidin-2-yl) benzene-1-sulfonamide, Brown solid, yield - 70\%, m.p - $260-270^{\circ} \mathrm{C}$. IR $\gamma\left(\mathrm{cm}^{-1}\right)(\mathrm{KBr}): 3045 \mathrm{~cm}^{-1}$ (C-H Ar str); $3290 \mathrm{~cm}^{-1}$ (N-H str); $1650 \mathrm{~cm}^{-1}$ $(\mathrm{HC}=\mathrm{N}) .{ }^{1} \mathrm{H}$ NMR $\delta$ ppm $(\mathrm{TMS}): 9.07(1 \mathrm{H}, \mathrm{S}, \mathrm{CH}=\mathrm{N}), 8.69-7.29(\mathrm{~m}, 11 \mathrm{H}$, Ar-H).

\section{Result on molecular docking studies of target molecules}

All the docked conformations for each compound were analyzed and it was found that the most favorable docking poses with a maximum number of interactions were those which were ranked the highest score based on the minimal binding energy, which was computed as a negative value by the MOE software. Then considering the root mean square deviation (RMSD) value, generally, acceptable range of the RMSD when the model is overlapped to the template is $2 \AA$. For protein-ligand docking, $2 \AA$ is good, and $1 \AA$ and less is great. However, this RMSD value may not be considered as the only criteria for evaluation of the model constructed. Some deviations at times can be considered. Based on this declaration, in this present report, the compounds showed that the RMSD value ranges between 1.0577 and 2.8925, and this result suggests that the synthesized compounds showed a good RMSD value.

The MOE software generated docking score of the all the molecules is summarized in Table 1 . The most favorable docking poses of the 10 docked conformations for each molecule were analyzed for further investigation of the ligand interactions within the active sites. The wonderful number of interactions with active site residues coupled with favorable binding energy states that these target molecules may serve as an effective replacement agent for the antimycobacterial drugs. These ligands showed a proper binding pattern and anchored tightly inside the active site canyon (Site I) of the protein. The 2D ligandprotein interactions were visualized using the MOE ligand interaction program for all the molecules as shown in Figs. 2-4.

The best docking poses of almost all the nine designed molecules were formed a single cluster inside the active site cleft of the receptor. Among these nine designed molecules, the best three molecules are S3, S5, and S8 ligand and they showed the best interaction within the receptor as shown in Figs. 2-4. The calculated surface analysis pocket for these molecules

Table 1: Docking results for sulfadiazine derivatives with protein PDB: 2NSD

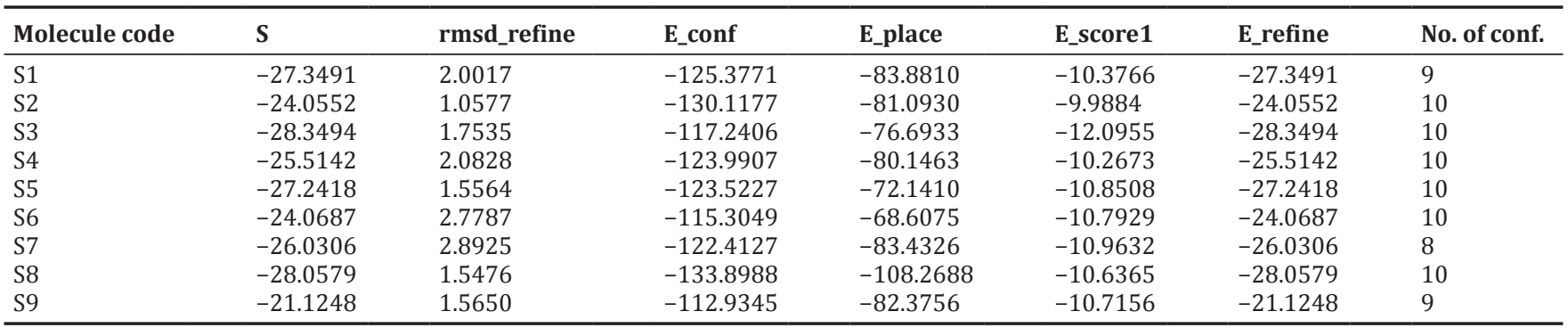

S: The final score, rmsd_refine: The root mean squar deviation between the pose before refinement and the pose after refinement, E_conf: The energy of the conformer. E_place: Score from the placement stage, E_score1: Score from the rescoring stage (s), E_refine: Score from the refinement stage, and No. of conf: number of conformations generated by ligand, PDB: Protein data bank 
was shown in Figs. 2-4. The molecules under consideration for further synthesis have a higher binding affinity with the receptors, in All the synthesized compounds have a higher binding affinity with the receptors (Protein ID: 2NSD) in the binding energy range of -28.3494 to -21.1248 $\mathrm{kcal} / \mathrm{mol}$ and the range of London $\mathrm{dG}$ is -10.9632 to $-09.9884 \mathrm{kcal} / \mathrm{mol}$.

Docking analysis reveals that the molecule S3 interacted with receptor through backbone acceptor with Gly 14 and side chain donor with Ser 20 (Fig. 2). The number of conformations generated by molecule S3 was 10 which indicated that flexibility is an important parameter for the ligand to dock deeply within the binding pocket of enoyl acyl reductase enzyme. The lowest docking score for molecule S3 was -28.3494 , which indicates that compound is active at this energy of conformation. Further, a careful calculation of surface analysis of the binding pocket of this molecule indicated that molecule S3 adopted a position in a hydrophobic cage surrounded by the following amino acids residue such as Tyr 158, Ile 16, Thr 196, Met 199, Pro 193, Phe 149, Ala 198, Gly 14, and Ser 20 and these were approach closely to the ligand for strong interactions.

Docking analysis reveals that the molecule S5 interacted with receptor through backbone donor with Ser 94 and side chain acceptor with Ser 94 and Ser 20 which is shown in Fig. 3. The number of conformations generated by molecule S5 was 10 , and the lowest docking score for molecule S5 was -27.2418 . The calculation of surface analysis showed the binding pocket of this molecule indicating that this molecule S5 adopted a position in a hydrophobic cage surrounded by the following

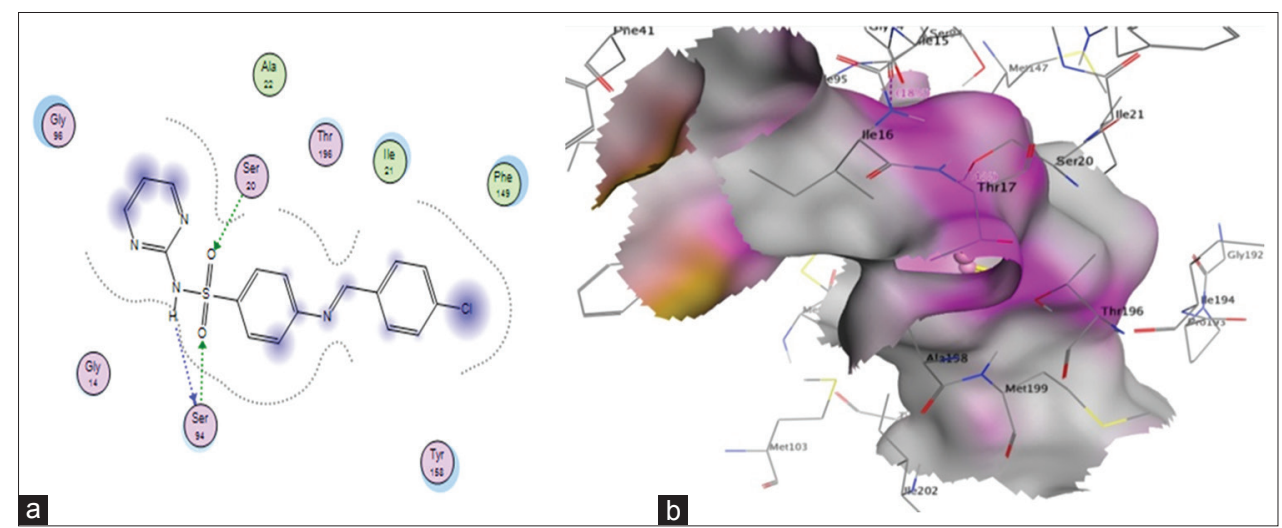

Fig. 2: ( $a$ and b) Ligand Receptor interaction and binding surface of compound S3 with 2NSD

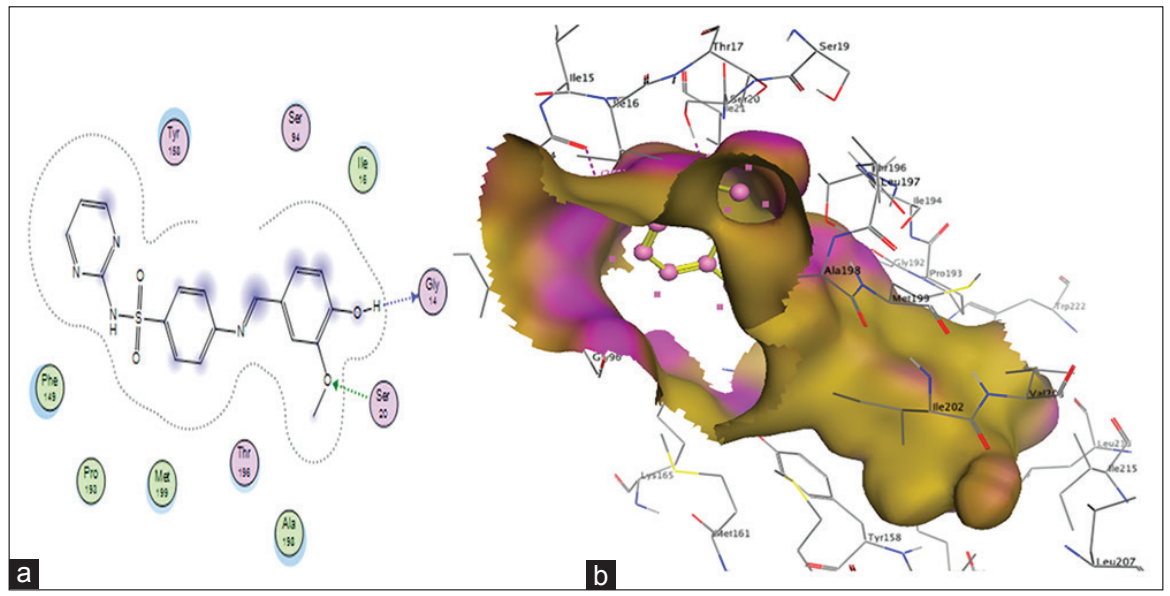

Fig. 3: (a and b) Ligand receptor interaction and binding surface of compound S5 with 2NSD

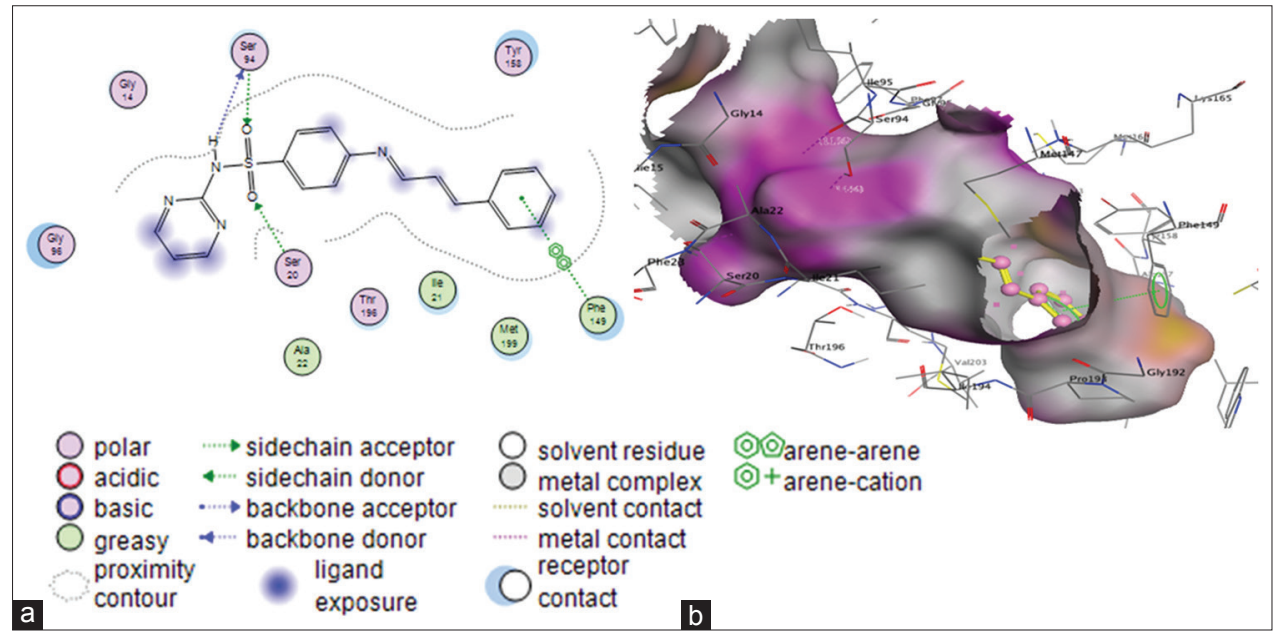

Fig. 4 (a-b): Ligand Receptor interaction and binding surface of compound S8 with 2NSD 
amino acids residue such as Gly 14, Gly 96, Ala 22 , Thr 196, Phe 149, Tyr 158, Ile 21, Ser 94, and Ser 20 for its strong interactions.

Docking analysis reveals that the molecule S8 interacted with receptor through backbone acceptor with Ser 94 and side chain donor with Ser 94 and Ser 20 which is shown in Fig. 4. The number of conformations generated by molecule S8 was 10 which indicates The total of 10 conformations was generated by a compound S8, which indicates that the flexibility of interaction of the ligand with the protein binding pocket of enoyl-acyl reductase enzyme. The lowest docking score for molecule S8 was -28.0579 . The calculation of surface analysis showed the binding pocket of this molecule indicating that this molecule S8 adopted a position in a hydrophobic cage surrounded by the following amino acids residue such as Gly 14, Gly 96, Thr 96, Ala 22, Tyr 158, Ile 21, Met 199, Ser 94, and Ser 20 for its strong interactions.

\section{CONCLUSION}

In-silico docking study of the target molecules (ligand) with enoyl-ACP reductase (receptor) were run; the results showed that the best docking score was obtained for the target molecules S3, S5, and, S8 among this nine designed molecules. Therefore, this effect is due to the presence of heterocyclic analog 4-\{(E)-[(phenyl) methylidene] amino $\}-\mathrm{N}$-(Pyrimidin2yl) benzene-1-sulfonamide moiety with its structure. On docking study results, it was quite understood that all the basic analog of this proposed molecules showed a best target-protein interaction through hydrogen bond acceptor, hydrogen bond donor, side chain acceptor, and side chain donor atoms/groups present in this molecules. Consequently, it is important to highlight that these atoms could also participate in arenearene interactions with some receptor amino acid residues. Hence, according to the present study, it can be suggested that the study of these nine sulfadiazine molecules could be the first step in the development of novel agent which can act as an antimycobacterial drug.

\section{AUTHOR'S CONTRIBUTIONS}

T. Prabha, who is fully contributed to prepare this whole manuscript write up, followed by plagiarism check if any, and to check the grammar using the grammarly online tool. Moreover, she is the one who runs the docking analysis using MOE 2009.10 software. T. Sivakumar, with his guidance, the author moved further to complete this work and also the final manuscript proofreading was done by him.

\section{CONFLICTS OF INTEREST}

The authors have no conflicts of interests.

\section{REFERENCES}

1. Cegielski JP, Chin DP, Espinal MA, Frieden TR, Rodriquez Cruz R, Talbot EA, et al. The global tuberculosis situation. Progress and problems in the $20^{\text {th }}$ century, prospects for the $21^{\text {st }}$ century. Infect Dis Clin North Am 2002;16:1-58.

2. Retno WR, Tatang I, Subagus W, Takushi K. Antituberculosis activity of extract and fractions of Tinospora crispa against mycobacterium tuberculosis h37rv using mycobacteria growth indicator tube and agar proportion method. Asian J Pharm Clin Res 2018;11:132-5.

3. Spigelman MK. New tuberculosis therapeutics: A growing pipeline. $\mathrm{J}$ Infect Dis 2007;196:S28-41.

4. Espinal MA. The global situation of MDR-TB. Tuberculosis 2003;83:44-51.

5. Ameen SM, Drancourt M. In vitro susceptibility of mycobacterium tuberculosis to trimethoprim and sulfonamides in France. Antimicrob Agents Chemother 2013;57:6370-1.

6. Argyropoulou I, Geronikaki A, Vicini P, Zanib F. Synthesis and biological evaluation of sulfonamide thiazole and benzothiazole derivatives as antimicrobial agents. Arkivoc 2009;6:89-102.

7. Hevener KE, Yun MK, Qi J, Kerr ID, Babaoglu K, Hurdle JG, et al.
Structural studies of pterin-based inhibitors of dihydropteroate synthase. J Med Chem 2010;53:166-77.

8. Gadad AK, Mahajanshetti CS, Nimbalkar S, Raichurkar A. Synthesis and antibacterial activity of some 5-guanylhydrazone/thiocyanato-6arylimidazo[2,1-b]-1,3, 4-thiadiazole-2-sulfonamide derivatives. Eur J Med Chem 2000;35:853-7.

9. Maren TH. Relatons between structure and biological activity of sulfonamides. Annu Rev Pharmacol Toxicol 1976;16:309-27.

10. Supuran CT, Scozzafava A, Jurca BC, Iiies MA. Carbonic anhydrase inhibitors-part 49: Synthesis of substituted ureido and thioureido derivatives of aromatic herterocyclic sulfonamides with increased affinities of isozyme I. Eur J Med Chem 1998;33:83-93

11. Bouissane L, El Kazzouli S, Léonce S, Pfeiffer B, Rakib EM, Khouili M, et al. Synthesis and biological evaluation of N-(7-indazolyl) benzenesulfonamide derivatives as potent cell cycle inhibitors. Bioorg Med Chem 2006;14:1078-87.

12. Camoutsis C, Geronikaki A, Ciric A, Soković M, Zoumpoulakis P, Zervou M, et al. Sulfonamide-1,2,4-thiadiazole derivatives as antifungal and antibacterial agents: Synthesis, biological evaluation, lipophilicity, and conformational studies. Chem Pharm Bull (Tokyo) 2010;58:160-7.

13. Weber A, Casini A, Heine A, Kuhn D, Supuran CT, Scozzafava A, et al. Unexpected nanomolar inhibition of carbonic anhydrase by COX-2selective celecoxib: New pharmacological opportunities due to related binding site recognition. J Med Chem 2004;47:550-7.

14. Li JJ, Anderson GD, Burton EG, Cogburn JN, Collins JT, Garland DJ, et al. 1,2-diarylcyclopentenes as selective cyclooxygenase-2 inhibitors and orally active anti-inflammatory agents. J Med Chem 1995;38:4570-8.

15. Owa T, Nagasu T. Novel Sulfonamide derivatives for the treatment of cancer. Exp Opin Ther Pat 2000;10:1725-40.

16. Ogden RC, Flexner CW. Protease Inhibitors in AIDS Therapy. Newyork, U.S.A: Marcel Dekker; 2001.

17. Dhar DN, Taploo CL. Schiff bases and their applications. J Sci Ind Res 1982;41:501-6.

18. Radha S, Mothilal KK, Thamaraichelvan A, Elangovan A. Synthesis, characterization and biological studies of sulfadiazine drug based transition metal complexes. J Chem Pharm Res 2016;8:202-11.

19. James S, Peter I, Jamie SS, Ian M. folate biosynthesis-reappraisal of old and novel targets in the search for new antimicrobials. Open Enz Inhi J 2008;1:12-33.

20. Knowles DJ. Advances in the discovery of novel antibacterial agents during the year 2002. Curr Med Chem 2004;11:2213-43.

21. Krátký M, Dzurková M, Janoušek J, Konečná K, Trejtnar $F$, Stolaříková $\mathrm{J}$, et al. Sulfadiazine salicylaldehyde-based schiff bases: Synthesis, antimicrobial activity and cytotoxicity. Molecules 2017;22:pii: E1573.

22. Jayaprakash R, Saroj KS, Hemalatha S, Easwaramoorthy D. Synthesis, characterization, quantitative structure-activity relationship, docking, antibacterial activity, and brine shrimp lethal studies on 1-phenylalanine schiff bases. Asian J Pharm Clin Res 2016;9:203-8.

23. Jithendra KK, Krishnamurthy G, Sunil K. Synthesis, Characterization, in vitro Antimicrobial, anthelmintic and docking studies of new 2-[(E)-\{[4-(1h-1,2,4-Triazol-1 Ylmethyl)Phenyl]Imino $\}$ Methyl] phenol, and their complexes with $3 \mathrm{~d}$ metal ions. Int J Pharm Pharm Sci 2016;8:134-9.

24. Vaibhav S, Dinesh KM, Rina D, Preet KK. Synthesis of some novel triazole derivatives as schiff bases and their antimicrobial evaluation. Int J Pharm Pharm Sci 2016;8:28-31.

25. Vijesh AM, Isloor AM, Telkar S, Arulmoli T, Fun HK. Molecular docking studies of some new imidazole derivatives for antimicrobial properties. Arab J Chem 2013;6:197-204.

26. Kapoor M, Gopalakrishnapai J, Surolia N, Surolia A. Mutational analysis of the triclosan-binding region of enoyl-ACP (acylcarrier protein) reductase from plasmodium falciparum. Biochem $\mathrm{J}$ 2004:381:735-41.

27. Peter CM. Marvin View: Molecule Applets for the World Wide Web. In: Third International Electronic Conference on Synthetic Organic Chemistry (ECSOC-3); 1999. p. 1-30.

28. Halgren A, Nachbar RB. Merck molecular force field. IV. Conformational energies and geometries for MMFF94. J Comput Chem $1996 ; 17: 587-615$. 